\title{
Immigration after Brexit: towards a more liberal approach?
}

\author{
Jonathan Portes* \\ King's College London / UK in a Changing Europe
}

Given how central immigration was to the Brexit vote, it is no surprise that the next Parliament is likely to see the biggest shake-up in UK immigration policy in 40 years.

What happens on Brexit will determine what happens on free movement, but any scenario is likely to see major changes, particularly for those migrating for work. There is relatively little controversy on what happens to European Economic Area citizens currently resident in the short term. They are already entitled to apply for 'settled status'. Labour would make this quasi-automatic and not subject to a time limit, removing the risk that large numbers will become 'irregular' in July 2021.

But for future migrants from the European Economic Area, free movement will end at the end of the transition period under Boris Johnson's deal. Moreover, the Conservative commitment to maintaining regulatory flexibility after Brexit, and the accelerated timetable for negotiating a trade deal with the EU, means that there is little prospect that there will be any significant provisions on labour mobility between the UK and the EU in any post-Brexit deal. Leaving aside the political constraints on the UK side, EU trade deals have not in the past included significant provisions relating to immigration, particularly given the complex division of competences between the EU institutions and member states on such issues.

This in turn will enable the Conservatives to keep their promise to introduce a new system that by and large (Irish citizens will remain an exception) treats EU and non-EU migrants similarly. However, describing it, as their manifesto does, as an 'Australianstyle points system' is inaccurate. The existing UK system for non-EU migrants has been notionally 'points based' since the late 2000s. Unlike the Australian system, those coming to the UK to work in most cases require a job offer, and the Conservatives do not propose to change that. There will also be special visas for NHS workers and a new, expanded seasonal scheme for agricultural workers. Indeed, in order to meet their promise to increase the number of NHS nurses by 50,000, the Conservatives have set a new target of recruiting 12,500 extra nurses from abroad.

Rhetorically at least, there is little difference between the main British parties when it comes to the shape of this new system. Labour argue that the immigration system 'must allow us to recruit the people we need, and to welcome them and their families. Our work visa system must fill any skills or labour shortages that arise'. The Liberal Democrats want a 'flexible merit-based system'. The SNP supports a continuation of free movement rights, and favours a more liberal system. Its manifesto proposes the devolution of migration powers to develop a Scottish migration system, tailored to distinctive Scottish needs and preferences for population growth. The devolution of migration policy is also supported by Plaid Cymru, allowing Wales to 'set its own migration quota'. 
In other words, all parties are promising a new system that responds to the needs of the economy (albeit of the nation they represent), with the Conservatives ditching the Cameron-May target to reduce net migration to the tens of thousands. This reflects an appreciation of the fact that the UK will need migrants. Ending free movement will make that more, not less, difficult and more expensive since all new migrants will be subject to the charges the Home Office imposes.

That we are having such debates reflects the fact that immigration is a less salient issue among the electorate, and that public perceptions of the economic and social impact of immigration on the UK are far more positive than they were at the time of the referendum. This has allowed the injection of a welcome note of realism into the debate as a consequence of which, largely regardless of the election outcome, the system for work-related migration is likely to be considerably less restrictive than that set out as recently as December 2018 by Theresa May.

Under the Conservatives, this new system would apply to all migrants (except Irish citizens). Under the Liberal Democrats, since we would remain in the EU and free movement would continue, it would only apply to those from outside the European Economic Area.

Labour's position is more complex. Their proposed Brexit deal would keep the UK 'closely aligned' with the single market, while free movement-an integral part of the single market-would be the 'subject of negotiations'. In practice, that is likely to mean that free movement, perhaps relabelled, would continue broadly as now, perhaps with some modest restrictions. Switzerland, for example, applies free movement rules but is in principle allowed to restrict eligibility for some vacancies to workers already resident.

Beyond work-related migration, considerable differences remain. Both Labour and the Liberal Democrats (as well as the SNP and the Greens) promise to abolish the 'minimum income requirement' for spouse visas, which prevents lower-earning British nationals from being joined here by their non-EU spouse. They will both, along with the SNP, end the hostile environment, reduce the use of immigration detention, and improve the treatment of asylum seekers and refugees. Taken together, these measures would make the UK considerably more open to non-economic migration than it is now.

Two parties propose machinery of government changes, to change the culture around the administration of migration policy. The Liberal Democrats would remove responsibility for much of immigration policy and delivery from the Home Office. The Greens propose splitting the Home Office into a Ministry of Sanctuary and a Ministry of the Interior.

We do not have enough detail to model the economic impacts of a new, post-Brexit immigration system. However, our analysis suggests that the net effect of removing free movement combined with a relatively liberal approach might reduce net migration by about 35,000 a year while having only a modest negative impact on GDP. Equally, a more restrictive approach along the lines originally proposed by Theresa May could reduce migration by about 55,000 a year and reduce GDP by 1.8 per cent over ten years.

So while in 2017 the UK seemed to be heading towards a much more restrictive regime, this is no longer the case. The net migration target has gone, and-Brexit or no Brexit-both economic and political pressures mean that the new regime is likely to be substantially more liberal than that envisaged by Theresa May. 
p. 88. Immigration after Brexit: towards a more liberal approach?

\section{Note}

1 This was reproduced from the UK in a Changing Europe publication, "Brexit: The Manifestos Uncovered.

* Correspondence address: Jonathan Portes, Professor of Economics and Public Policy and Senior Fellow, UK in a Changing Europe, Department of Political Economy, King's College London. Email: jonathan.portes@kcl.ac.uk 